\title{
O Lugar da Ética e Bioética nos Currículos de Formação Médica
}

\section{The Place of Ethics and Bioethics in Medical Education}

\author{
Annatália Meneses de Amorim Gomes ${ }^{1}$ \\ Escolástica Rejane Ferreira Moura ${ }^{2}$ \\ Rosendo Freitas Amorim ${ }^{3}$
}

PALAVRAS-CHAVE

- Ética;

- Bioética;

- Educação Médica;

- Currículo.

KEY-WORDS

- Ethics;

- Bioethics;

- Education, Medical;

- Curriculum.

Recebido em: 03/01/2006

Reencaminhado em: 18/04/2006

Aprovado em: 21/06/2006

56 REVISTA BRASILEIRA DE EDUCAÇÃO MÉDICA

\footnotetext{
Curso de Educação em Saúde da Universidade de Fortaleza, Fortaleza, Ceará, Brasil.

2 Departamento de Enfermagem, Universidade Federal do Ceará, Fortaleza, Ceará, Brasil.

${ }^{3}$ Universidade de Fortaleza, Fortaleza, Ceará, Brasil.
}

\begin{abstract}
The aim of this documental study was to verify the offer, number of hours per class and percentage of disciplines involving Ethics and Bioethics in Medical Education; to analyze the transversal character of Ethics and Bioethics; to identify the thematic lines highlighted in the specific disciplines and to study the aspect of multiprofessionality of the docent body. There is some room for Ethics and Bioethics in the $1^{\text {st }}, 5^{\text {th }}$ and $8^{\text {th }}$ semesters of the Medical Program of the Federal University of Ceará (UFC), summing up 196 hours, and transversally they are to a certain extent inserted in a good deal of the other disciplines of the program, an aspect that would deserve being incorporated into the Program of the University of the State of Ceará- UECE. The thematic lines incorporated in the two universities show a widened perception of Deontology itself, not only focused on duties but also contemplating new demands arising from the socio/ cultural phenomenon involved. The UECE's professors showed a broader professional diversity than the docent body of the UFC. We suggest that the changes in terms of a reform of the course programs proposed at the Universities be followed and evaluated by the proper beneficiaries, thus contributing to their personal and professional growth.
\end{abstract}




\section{INTRODUÇÃO}

No âmbito filosófico, a moral é o sistema de normas, princípios e valores que orientam o comportamento das pessoas nas diversas sociedades; e a ética é compreendida como a reflexão crítica sobre a moral, guardando estreita articulação com esta, no terreno dos valores ou das virtudes, presentes no pensamento reflexivo e nas ações cotidianas. Nesse sentido, o senso e a consciência moral dizem respeito aos valores, aos sentimentos, às intenções, decisões e ações referidas ao bem, ao mal e ao desejo de felicidade; dizem respeito às relações que mantemos com os outros e, portanto, nascem e existem como parte de nossa vida intersubjetiva ${ }^{1}$.

Nessa perspectiva, o campo ético é constituído, pois, pelos valores e obrigações que formam o conteúdo das condutas morais, especialmente das virtudes. Estas são realizadas pelo sujeito ético, pessoa que só pode existir preenchendo as condições de ser consciente de si e dos outros, ser dotado de vontade, ser responsável e ser livre, no sentido de poder se determinar. Sobre esse assunto, é assinalado que a maturidade humana é alcançada, sobretudo, no estádio ético, ou seja, na fase em que o homem, autônomo e livre, age segundo valores adequados ao seu modo de existir ${ }^{2}$.

A partir dos anos 1970, os avanços tecnológicos nas áreas da Biologia e da Genética, incluindo o Projeto Genoma dos novos medicamentos a serem testados; a clonagem humana; e as novas tecnologias da informação (NTI), pelo advento da internet e da globalização da informação, provocaram o recrudescimento das discussões sobre a Ética e a Bioética, marcadamente no espaço acadêmico. $\mathrm{O}$ enfoque central em torno dessa discussão é o conceito de ser humano, que corresponde ao Homo complexus, trazendo em si caracteres antagonistas, bipolarizados, existindo ao mesmo tempo unidade e dualidade entre Homo faber (técnica), Homo ludens (lúdico), Homo sapiens (racionalidade) e Homo demens (louco) ${ }^{3}$. Ainda segundo o mesmo autor, o desenvolvimento do conhecimento racional, empírico e técnico jamais anulou os conhecimentos simbólicos, míticos, mágicos ou poéticos, ao que Dom Padin ${ }^{4}$ complementa, sob uma abordagem espiritual, definindo que as realidades corpóreas na vida humana são dirigidas pelo espírito, ou seja, os valores éticos e espirituais se sobrepõem aos valores econômicos e políticos.

A Bioética compreende um amplo campo filosófico, científico e sociopolítico, e integra duas vertentes do conhecimento humano: o saber simbólico, que explicita e esclarece os sentidos da realidade; e o saber científico, que explica seu objeto de estudo específico. A partir da Bioética, esses dois saberes se complementam e se integram. Ocorre crescente interesse pela reflexão e formulação de saberes sobre o compor- tamento moral do profissional médico e a ética da vida sob diversas dimensões: filosófica, religiosa, social, política, legal e econômica, apenas para enumerar as mais significativas²

Transpondo essas considerações para a formação médica, defende-se a idéia de que o estudo da Ética e da Bioética deva constituir prioridade, uma vez que esses profissionais se ocupam do cuidado da saúde de pessoas, de seres humanos. Apesar da necessidade indiscutível do conhecimento técnico, cada vez mais se reconhece a premência da dimensão humana do cuidado no campo da saúde. O encontro intersubjetivo do cuidar inerente à relação médico-paciente mostra-se singular, pois ocorre em momento de vulnerabilidade, dor ou incerteza, revestido de projeções fundadas no poder do saber médico que permeia essa relação, tendo um componente ético imprescindível.

A fundamentação teórica da Medicina a situa no plano de intersecção das ciências biológicas com as humanas e sociais, o que torna a atividade profissional uma práxis relacional e uma entidade social, sendo que todas essas dimensões comportam uma moralidade e uma cientificidade bastante complexas ${ }^{5}$. Provavelmente por isso, o saber sobre a Ética na formação do médico constitui uma preocupação desde o mundo antigo e de diversas civilizações, buscando-se disciplinar moralmente a conduta dessa categoria profissional.

Hipócrates sintetizou a teoria médica na Grécia, e seu juramento fundamenta os códigos de Ética da profissão médica até os dias atuais. Ele instaurou, com isso, a Medicina como atividade racional, distanciando-a do caráter místico e religioso, e imprimindo a marca da generosidade e do amor ao próximo no exercício da profissão ${ }^{6}$.

Nos últimos 30 anos, muitos fatores contribuíram para tornar esse campo emergente, entre eles o esgotamento do modelo biomédico centrado na doença e não na pessoa, com menor ênfase nas ações preventivas e promocionais; crescente avanço e destaque técnico-científico, em detrimento dos aspectos sociais, culturais, psicológicos, econômicos e políticos presentes no processo saúde-doença; mercantilização da Medicina, na qual o cuidado se transformou em mercadoria, apenando o caráter social da prática; desgaste das condições de trabalho e desvalorização profissional, bem como o enfrentamento dos paradigmas éticos no mundo da complexidade, cuja marca é a rápida mudança da realidade.

Esse contexto sociocultural da sociedade atual, fragmentada e velozmente cambiante, atinge radicalmente o ensino da Medicina, que passa a se caracterizar pela supervalorização de aspectos técnicos e econômicos da atividade médica, levando a um desgaste dos padrões éticos na prestação de serviços médicos, alargado nos meios de comunicação e pre- 
senciado em cenas do cotidiano. Esta asserção se confirma ao afirmarem que o paradigma biotecnicocientífico no campo da Biomedicina traz acelerada incorporação tecnológica à prática médica, comprometendo a relação afetiva e efetiva médicopaciente, o que, por sua vez, subestima a ética nessa relação ${ }^{7}$.

Partindo da constatação de que Ética e Bioética são fundamentais à formação médica e de sua efervescência no momento atual, passou-se a elaborar os seguintes questionamentos: Como esse conteúdo está inserido no currículo da Medicina (disciplinas específicas, semestres, horas-aula)? Qual a sua disposição em relação às demais disciplinas (transversalidade)? Quais as linhas temáticas que compõem o corpo das disciplinas? E quais formações compõem o corpo docente da graduação médica (multiprofissionalidade)?

Portanto, o objeto deste estudo corresponde ao lugar da Ética e Bioética na formação médica, tendo sido desenhado com os seguintes objetivos: verificar semestres de oferta, horas-aula e porcentagem com que disciplinas específicas voltadas para o saber da Ética e Bioética se apresentam no currículo da Medicina; averiguar o caráter da transversalidade do conteúdo de Ética e Bioética nas demais disciplinas; identificar as linhas temáticas que sobressaem nos conteúdos das disciplinas específicas; e analisar o aspecto da multiprofissionalidade no corpo docente da Medicina.

\section{MATERIAL E MÉTODO}

Trata-se de pesquisa documental, realizada por meio de revisão das ementas de disciplinas dos currículos de Medicina de duas universidades públicas do Ceará: Universidade Estadual do Ceará (UECE), Fortaleza; e Universidade Federal do Ceará (UFC), Fortaleza. Os currículos foram disponibilizados pelas coordenações dos respectivos cursos, e a coleta dos dados foi efetuada em abril de 2004. Ressalta-se que o emprego complementar de métodos qualitativos para abordar este objeto de estudo poderia consolidar ou mesmo refutar os dados encontrados nesta pesquisa, pois o fato de determinados conteúdos integrarem a ementa de uma disciplina não pressupõe seu desenvolvimento pelo corpo docente.

Os dados foram coletados por meio de leitura cuidadosa e aprofundada de cada ementa de disciplina. A seleção de disciplina específica de Ética e Bioética tomou por base o critério de conter em seu enunciado ou na ementa uma ou mais das seguintes palavras-chave: Ética, Bioética, Deontologia ou Medicina Legal, direitos do paciente e sigilo profissional. Para a identificação da transversalidade, as disciplinas também foram selecionadas pelo mesmo critério. Os demais dados foram selecionados nos currículos, conforme a pertinência de responder aos objetivos propostos e descrever o objeto de estudo.
A pesquisa documental fundamenta-se no levantamento de documentos, escritos ou não, podendo ser retrospectivos ou contemporâneos, buscando tratar analiticamente materiais de acordo com o objeto da pesquisa ${ }^{8,9}$.

Os resultados foram organizados em quatro tabelas, que reuniram as informações correspondentes às seguintes categorias: inserção das disciplinas específicas voltadas para Ética e Bioética nos currículos de Medicina (UFC e UECE); transversalidade dos conteúdos de Ética e Bioética no currículo de Medicina; linhas temáticas referentes a Ética e Bioética inseridas no corpo das disciplinas; e diversidade profissional do corpo docente da graduação em Medicina. Além disso, apresentou-se uma caracterização geral dos currículos de formação médica das duas universidades.

As coordenações dos cursos de Medicina foram informadas sobre a realização do estudo na ocasião em que foram solicitados os documentos e matrizes curriculares.

\section{RESULTADOS E DISCUSSÃO}

\section{Caracterização geral dos currículos de formação médica - UFC e UECE}

O curso de Medicina da UFC consolidou, em 2001, sua última reforma curricular, desenhando um Plano PolíticoPedagógico (PPP) com modificações em sua filosofia e estratégia educacional, originando outra matriz curricular que melhor atendesse as necessidades da sociedade. Essa mudança resultou de estudos e formulações por parte dos docentes, discentes, pessoas da administração e de consultoria especializada. A UECE implantou o curso de Medicina, em 2002, elaborando, pois, seu primeiro PPP.

O currículo de Medicina da UFC está composto por módulos seqüenciais e integrados, distribuídos em 12 semestres, com cada período letivo, correspondendo a 100 dias. Os conteúdos obrigatórios contidos nos módulos estão organizados por sistemas, módulos longitudinais (desenvolvimento pessoal e atenção básica) e internato. Os conteúdos complementares são oferecidos em disciplinas optativas. A carga horária total do curso soma 9.080 horas-aula, incluindo 4.488 horas do internato de dois anos ${ }^{10}$.

O currículo do curso da UECE dispõe os conteúdos em módulos sucessivos de aprendizagem, compostos por um conjunto de disciplinas. A carga horária total das disciplinas é de 6.984 horas, incluindo 1.880 horas relativas ao internato, distribuídas em 12 semestres, em períodos letivos de 100 $\operatorname{dias}^{11,12}$.

Ambas as universidades caracterizam o perfil da formação médica como generalista, humanístico, crítico e reflexivo, 
comprometido com a defesa da vida, da cidadania, da responsabilidade social e com a promoção da saúde integral do ser humano, respeitando os princípios éticos na perspectiva da interdisciplinaridade e da intersetorialidade da atenção em saúde ${ }^{10,11}$.

Para o alcance desse perfil, o processo ensino-aprendizagem se baseia, nos dois universos pesquisados, em um conjunto de técnicas e métodos que inclui: estudo de caso, situação-problema real, discussão em sessão clínica, participação em eventos científicos, mesa-redonda, painéis e, principalmente, aprendizagem baseada em problemas (Problem $\mathrm{Ba}$ sed Learning - PBL) nas disciplinas em que o método se mostra adequado.

O PBL favorece a obtenção de conhecimentos pelo aluno e o desenvolver de habilidades e atitudes com relação à temá- tica em estudo. É um método centrado no aluno, desenvolvido por meio de grupos tutoriais (cada professor é responsável por até oito alunos), que discute os problemas no contexto clínico por meio de processo ativo, cooperativo, integrado e interdisciplinar. Estimula a capacidade de aprender a aprender do estudante, trabalhar em equipe, ouvir outras opiniões e assumir um papel proativo e também responsável por seu aprendizado. Cerca de $10 \%$ das escolas de Medicina em todo o mundo têm o PBL como método central de ensino-aprendizagem $^{13}$, o que enseja expectativa positiva para com o método adotado nos cursos do Ceará.

\section{Inserção das disciplinas específicas voltadas para Ética e Bioética nos currículos de Medicina (UFC e UECE)}

TABELA 1

Distribuição das disciplinas específicas de Ética e Bioética, segundo o semestre de oferta, horas-aula e porcentagem relativa à carga horária total10,11,12

\begin{tabular}{c|c|c}
\hline Disciplinas & Semestre & $\begin{array}{c}\% \text { Relativa às } \\
\text { Horas-Aula } \\
\text { Horas-Aula Total }\end{array}$ \\
\hline
\end{tabular}

UFC

\begin{tabular}{c|c|c|}
\hline Evolução histórica, científica e ética da Medicina & $1^{\mathrm{o}}$ & 68 \\
\hline Bioética e Cidadania & $5^{\mathrm{o}}$ & 64 \\
\hline Medicina Legal e Deontologia Médica & $8^{\mathrm{o}}$ & 64 \\
\hline
\end{tabular}

UECE

\begin{tabular}{c|c|c|}
\hline Ética e Bioética & $7^{\mathrm{o}}$ & 72 \\
\hline Medicina Legal e Deontologia & $8^{\mathrm{o}}$ & 72,1 \\
\hline
\end{tabular}

O perfil do profissional médico deve incluir postura ética, humanização nas relações, compromisso com a cidadania e senso de responsabilidade social. Para tanto, espera-se que a sua formação seja desenvolvida por meio de um processo ensino-aprendizagem que privilegie o conteúdo de Ética e Bioética.

Conforme se apresenta na Tabela 1, nos cursos da UFC, os conteúdos de Ética e Bioética integram três disciplinas específicas nessa área do conhecimento, sendo todas obrigatórias e totalizando 196 horas-aula. Na UECE, duas disciplinas são oferecidas com finalidade semelhante, totalizando 144 horas-aula.
Logo no $1^{\mathrm{o}}$ semestre, o curso da UFC oferece a disciplina Evolução Histórica, Científica e Ética da Medicina, aspecto retomado no $5^{\circ}$ e no $8^{\circ}$ semestres com outras duas disciplinas, respectivamente. A incorporação de conteúdos sobre Ética e Bioética em diferentes semestres do curso e com início bem precoce demonstra a preocupação de trabalhar a temática ao longo de todo o processo de formação do médico, contribuindo para que este estabeleça bases mais sólidas de atitudes, firmadas em valores morais e éticos. Além disso, iniciar o curso com uma visão da Ética e da Bioética desde o $1^{\circ}$ semestre permite maior compreensão das situações vivenciadas à luz de uma visão filosófica e não meramente técnica. Tal benefício não pôde ser 
analisado na perspectiva do currículo da UECE, cujas disciplinas voltadas para a temática são oferecidas a partir do $7^{\circ}$ semestre, bem mais do que na metade do curso.

A avaliação do ensino sobre a Ética realizada em 79 escolas de Medicina no Brasil constatou que este está voltado, quase exclusivamente, para a Deontologia, sendo que $90 \%$ das escolas tratam sobre Ética nas disciplinas de Medicina Legal e de Deontologia, e de 8.640 horas-aula, somente $0,6 \%$ da carga integral é dedicada à Ética ${ }^{14}$. Tomando por base esse estudo, infere-se que os cursos de Medicina das universidades públicas do Ceará conseguiram introduzir uma porcentagem mai- or do componente ético em seus currículos. O modelo clássico de ensino sobre a Ética e Bioética baseado na Deontologia (estudo de código de normas), porém, tornou-se inadequado e insuficiente para atender a necessária formação humanística do médico e perdeu a capacidade de resposta para os dilemas ético-morais suscitados pelos avanços das ciências, requerendo modificações, como a transversalidade dos conteúdos de Ética e Bioética ao longo das formações ${ }^{14}$.

\section{Linhas temáticas referentes a Ética e Bioética inseridas} no corpo das disciplinas (UFC e UECE)

TABELA 2

Distribuição dos conteúdos das disciplinas específicas de Ética e Bioética ${ }^{10,11,12}$

\begin{tabular}{|c|c|c|}
\hline \multirow[b]{3}{*}{ UECE } & Disciplinas & Conteúdos \\
\hline & Ética e Bioética & $\begin{array}{l}\text { Aplicação da Filosofia ao campo da saúde, pesquisa, prática clínico-cirúrgica e } \\
\text { coletiva, promoção e prevenção, destacando crenças, visão de mundo, liberdade, } \\
\text { parceria, interesse e responsabilidade que orientam ações. }\end{array}$ \\
\hline & $\begin{array}{l}\text { Medicina Legal e } \\
\text { Deontologia }\end{array}$ & $\begin{array}{l}\text { Aspectos prático-legais da profissão. Responsabilidade, direitos e deveres do médico. } \\
\text { Conduta em situações críticas: morte, situação de emergência. Comunicação de más } \\
\text { notícias e perdas a paciente e familiares. Prescrição de medicamentos, atestados e } \\
\text { licenças. Relação médico-paciente: aspectos éticos e direitos dos pacientes crônicos, } \\
\text { terminais, com neoplasias. Aspectos éticos e também legais em transplante. O médico } \\
\text { e a saúde pública: doenças de notificação compulsória. A morte e os fenômenos } \\
\text { cadavéricos. Legislação. Eutanásia. Problemas médico-legais relativos a identidade, } \\
\text { traumatologia, tanatologia, infortunística, sexologia e matrimônio. }\end{array}$ \\
\hline \multirow{3}{*}{ UFC } & $\begin{array}{l}\text { Evolução Histórica, } \\
\text { Científica e Ética da } \\
\text { Medicina }\end{array}$ & $\begin{array}{l}\text { História da Medicina. Evolução do raciocínio clínico na Medicina desde Hipócrates } \\
\text { aos nossos dias, levando em consideração as contribuições herdadas da Filosofia, da } \\
\text { Ciência Moderna e da Ética Médica, Bioética e Ciências. O estudante de Medicina e } \\
\text { as entidades médicas. Bioética e clínica (estudo de casos). }\end{array}$ \\
\hline & Bioética e Cidadania & $\begin{array}{l}\text { O estudo das implicações éticas de uma ação transdisciplinar em face dos desafios } \\
\text { epistemológicos contemporâneos, novos paradigmas em atenção à saúde. A posição } \\
\text { da Bioética como balizadora da legitimidade profissional na área da saúde. A relação } \\
\text { médico-paciente pelo prisma da Bioética. }\end{array}$ \\
\hline & $\begin{array}{c}\text { Medicina Legal e } \\
\text { Deontologia Médica }\end{array}$ & $\begin{array}{l}\text { Aspectos práticos e também legais da profissão. Responsabilidades, direitos e } \\
\text { deveres do médico. Conduta em situações críticas: morte, situação de emergência. } \\
\text { Comunicação de más notícias e perdas a pacientes e familiares. Prescrição de } \\
\text { medicamentos, atestados e licenças. Relação médico-paciente: aspectos éticos e } \\
\text { direitos dos pacientes crônicos, terminais, com neoplasias. Aspectos éticos, bem como } \\
\text { legais em transplantes. O médico e a saúde pública: doenças de notificação } \\
\text { compulsória. A morte e os fenômenos cadavéricos. Legislação. Eutanásia. Problemas } \\
\text { médico-legais relativos a identidade, traumatologia, tanatologia, infortunística, } \\
\text { sexologia e matrimônio. }\end{array}$ \\
\hline
\end{tabular}


A disciplina Medicina Legal e Deontologia em ambas as universidades trata dos aspectos legais e práticos da profissão, bem como dos direitos e deveres dos médicos, da relação médico-paciente, do fenômeno e da experiência da morte, da eutanásia e dos direitos e deveres dos pacientes, mostrando uma ampliação na percepção da própria Deontologia, focada não só em deveres, mas incluindo também aspectos do cotidiano da prática médica e com novas exigências da sociedade e dos fenômenos socioculturais envolvidos.

A Ética não poderia ser ensinada por meio de lições de moral, mas formar-se nas mentes, com base na consciência de que o humano é, ao mesmo tempo, indivíduo, parte da sociedade e parte da espécie ${ }^{3}$.

Há entre as duas universidades outros pontos em comum, podendo-se mencionar a busca de uma formação médica que atenda os anseios da sociedade e prepare cidadãos que reúnam competência técnica e humana; o fato de estarem iniciando um novo ciclo, quer pela primeira turma, pioneira e precursora nesta empreitada, que levará a aperfeiçoamentos (como no caso da UECE), quer pelo desafio de implementar um novo paradigma no curso de Medicina da UFC. Esta última, apesar da experiência acumulada de meio século, tenta se desvincular de conceitos arraigados para atender as demandas dos novos tempos.

O conteúdo da disciplina Ética e Bioética da UECE tem base filosófica articulada com as visões de mundo e comportamento em sociedade. Na UFC, a Ética vem contextualizada na evolução histórica e científica da Medicina, trabalhando a cidadania e a relação médico-paciente pelo enfoque da Bioética, visando a uma ação interdisciplinar. A dimensão da cidadania, em seu sentido mais amplo, configura o exercício dos direitos e deveres, ou seja, respeito à dignidade humana, fator indispensável a uma prática integral e focada nas necessidades sociais.

Apesar das disposições expressas nas sínteses das disciplinas, fica o questionamento: Como o aluno aprende a ser? A ver a si mesmo no seu projeto de vida, no sentido que atribui a esta formação e a sua própria vida, nesta relação com o cliente-família e com a sociedade? A este respeito, destaca-se a importância da educação integral do ser humano, dirigida à totalidade do ser e não apenas a um de seus componentes, na qual a universidade se dirija à sua missão de estudo do universal:

A Universidade poderá, assim, vir a ser um local de aprendizagem da atitude transcultural, transreligiosa e do diálogo entre a arte e a ciência, eixo da reunificação entre a cultura científica e a cultura artística. A Universidade remodelada será o lar de um novo tipo de humanismo ${ }^{15}$.
A vida cotidiana propicia eventos que exigem dos indivíduos que os vivenciam um posicionamento diante da realidade. Esses eventos podem ser julgados como certos ou errados, ou ocorrer dúvidas sobre as melhores escolhas, desencadeando conflitos quanto ao senso de justiça e de certeza. Situações práticas que levam a juízo de valor, ou seja, de aprovar ou desaprovar, são denominadas ações morais, as quais variam conforme a história do homem, seus interesses políticos, econômicos, sociais e características culturais dominantes. Uma sociedade é tanto mais rica moralmente quanto mais possibilidades oferecer a seus integrantes de assumirem a responsabilidade pessoal e/ou coletiva por seus atos.

\section{Transversalidade do conteúdo de Ética e Bioética nos currículos de Medicina (UFC e UECE)}

A transversalidade do aspecto ético no currículo da formação médica da UFC foi identificada quando, em ementas de disciplinas da maior parte dos semestres, o conteúdo de Ética se encontrava inserido, inclusive no internato. Esse achado demonstra avanço sobre o vínculo de integração e desintegração na atividade educacional, aspecto, porém, não reconhecido no currículo do curso da UECE, onde a Ética apareceu transversalmente em apenas três disciplinas e em semestres já bem adiantados.

Segundo Morin ${ }^{3}$, a complexa natureza humana é desintegrada na educação que se baseia em disciplinas, tornando-se impossível aprender o que significa ser humano. Assim, e preciso restaurar a unicidade para que cada ser humano tome consciência de sua identificação complexa e de sua identidade comum aos outros humanos, convocando à democracia e à cidadania terrestre. Portanto, é preciso reconhecer a unicidade e a complexidade humanas, reunindo e organizando conhecimentos das Ciências da Natureza, Humanas, Literatura e Filosofia, elo indissociável da unidade e diversidade de tudo o que é humano.

A educação, como processo amplo, não deve se limitar apenas à apreensão da realidade, mas também deve abarcar o aprender a pensar sobre o próprio processo de conhecimento, num constante movimento reflexivo. O tema da Ética guarda sua especificidade como eixo norteador, mas deve se inserir no curso como tema transversal, pois as questões que se abordam nas demais disciplinas se reportam sempre às implicações de valores morais, objetos da reflexão ética presentes nas relações humanas e na vida acadêmica. Neste sentido, chama-se a atenção para o não-reconhecimento do paciente como sujeito que pode estar relacionado à formação médica, pois, não produzindo preocupações nos estudantes sobre as conseqüências de seus atos, torna-se difícil que estes reconhe- 
TABELA 3

Distribuição de outras disciplinas do currículo de Medicina que trazem o conteúdo Ética e Bioética em suas ementas e respectivos semestres de oferta ${ }^{10,11,12}$

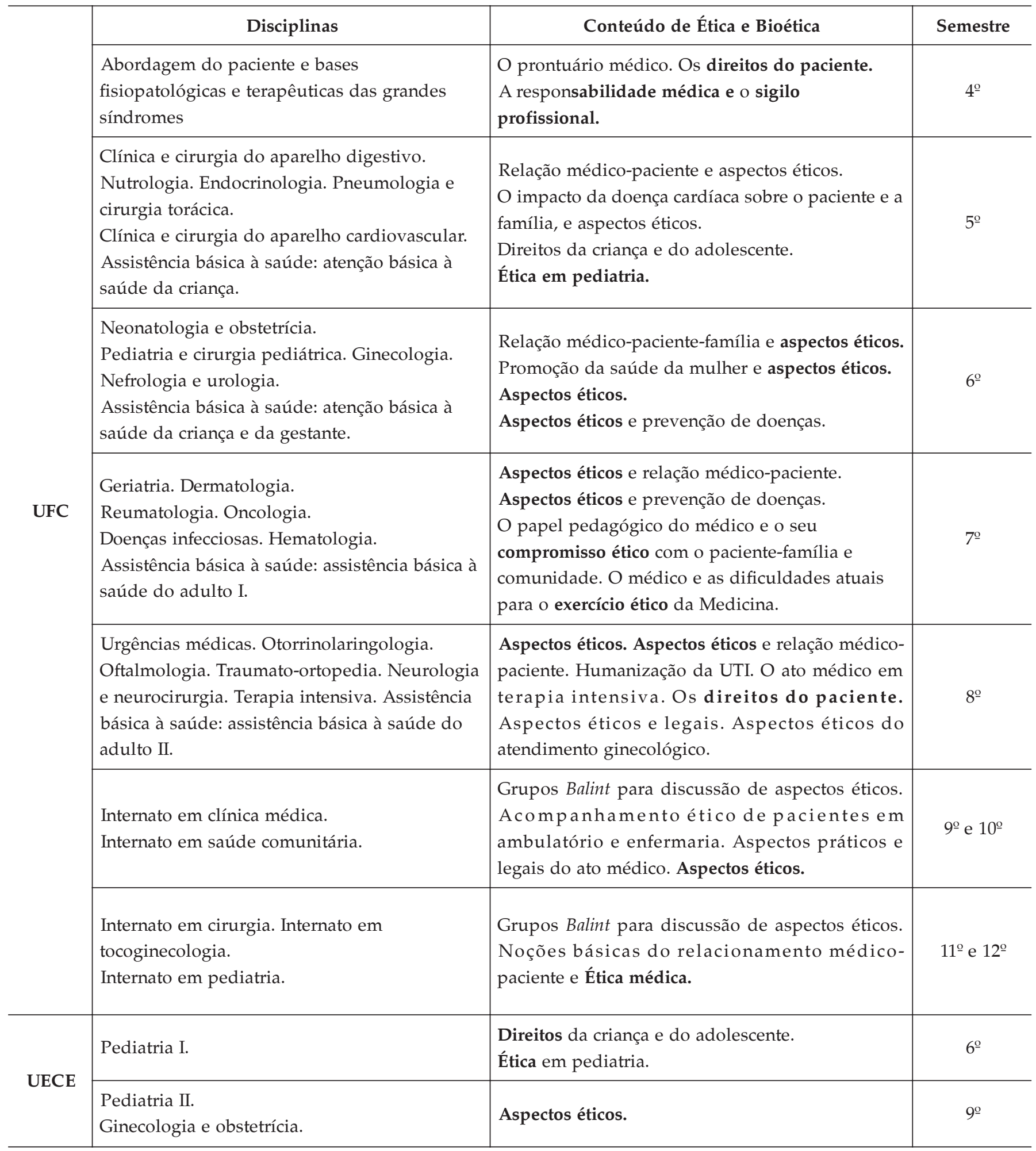


çam como dilemas as questões de cunho moral ${ }^{16}$. A Ética, portanto, deve ser transversal à proposta educacional do curso de Medicina e estar presente em cada plano e execução das diferentes disciplinas, com cada professor.

A identidade se constitui ao longo da vida a partir de identificações com pessoas ou papéis vivenciados. Na formação do médico, essa identidade ocorre com o paciente, em especial nos primeiros anos e, a partir do terceiro ano, com os professores. Em anos posteriores, ela se revela em atitudes na relação com o cliente e no próprio exercício da Medicina. Isso implica dizer que, caso não encontre professores, além de competentes, dedicados, humanos e compreensivos, a continência emocional não poderá ocorrer, e as defesas psíquicas diante das angústias poderão tornar-se tão freqüentes que uma parte do jovem estudante se aliena do humano ${ }^{17}$.

Em estudo para identificar o momento mais apropriado para a inserção do tema de Ética no curso de Medicina da Universidade Estadual de Londrina (UEL), a maioria dos alunos da disciplina Deontologia e Bioética sugeriu que o tema fosse introduzido ao longo da graduação. Alguns passos importantes foram dados nesse sentido, sobretudo em buscar reformas nos currículos de Medicina. Em 1985, o Conselho Federal de Medicina (CFM) emitiu um relatório elaborado pela Comissão de Ensino Médico no sentido de que o conteúdo da Ética Médica fosse ministrado como disciplina autônoma ao longo de todo o curso, mediante a discussão de casos reais e com a participação dos alunos ${ }^{14}$.

O relatório Delors, elaborado pela Comissão Internacional para Educação no Século XXI e editado, em 1998, pela Organização das Nações Unidas para a Educação, Ciência e Cultura (Unesco), estabelece os quatro pilares da educação contemporânea: aprender a ser, a fazer, a viver juntos e a conhecer, sendo a condição humana o objeto essencial de todo ensino, o qual deve levar em conta as dimensões éticas do humano. Aprender a conhecer significa a aprendizagem de métodos que nos ajudem a distinguir o que é real do que é ilusório; aprender a fazer se refere a escolher uma profissão e adquirir os conhecimentos e técnicas a ela associadas; aprender a conviver significa reconhecer-se a si mesmo na imagem do outro e acatar normas compreendidas e aceitas pelas pessoas que regem as relações coletivas; aprender a ser significa questionar certezas, crenças e condicionamentos para descobrir o que existe de consciente, o que exige uma dimensão ética ${ }^{15}$.

Diversidade profissional do corpo docente da
graduação em Medicina (UFC e UECE

TABELA 4

Distribuição do corpo docente* dos cursos de Medicina, por área de formação - UFC e UECE10,11,12

\begin{tabular}{|c|c|c|c|}
\hline Universidade & Formação do Docente & $\mathrm{Fa}$ & $\%$ \\
\hline \multirow{7}{*}{ UFC } & Medicina & 60 & 88,1 \\
\hline & Farmácia & 16 & 5,4 \\
\hline & Biologia & 6 & 2,0 \\
\hline & Medicina Veterinária & 6 & 2,3 \\
\hline & Odontologia & 3 & 1,0 \\
\hline & Enfermagem & 3 & 1,0 \\
\hline & Estatística & 1 & 0,3 \\
\hline \multicolumn{2}{|r|}{ Total } & 295 & 100 \\
\hline \multirow{7}{*}{ UECE } & Médico & 29 & 42,0 \\
\hline & Enfermeiro & 6 & 8,7 \\
\hline & Farmacêutico & 7 & 10,1 \\
\hline & Biólogo & 6 & 8,7 \\
\hline & Ciências Sociais & 4 & 5,8 \\
\hline & Ciências Humanas (Letras, Psicologia e Filosofia) & 6 & 4,8 \\
\hline & Outros & 10 & 20,8 \\
\hline \multicolumn{2}{|r|}{ Total } & 68 & 100 \\
\hline
\end{tabular}

*Inclui docentes de outras unidades de ensino com atuação no curso. 
O caráter multiprofissional foi reduzido no corpo docente da UFC, uma vez que, do total de 295 professores, 88,1\% são médicos, 5,4\% farmacêuticos, 2\% das áreas de Biologia e Medicina Veterinária. Não há nenhum professor graduado em Ciências Sociais e Humanas, o que demonstra a predominância do caráter biomédico na composição do corpo docente. Interroga-se até que ponto esse aspecto interferirá na implementação do novo currículo, repleto de conteúdos éticos e relacionados à subjetividade na relação médico-paciente.

Na UECE, dos 68 professores, 29 são médicos, correspondendo a $42 \%$ do total de professores, ao passo que $27,2 \%$ estão distribuídos entre enfermeiros, farmacêuticos e biólogos. Há também professores formados em Ciências Sociais (5,8\%) e Ciências Humanas $(4,8 \%)$, incluindo os cursos de Letras, Psicologia e Filosofia.

Essa diversidade de formação dos professores pode favorecer a geração de um conhecimento multidisciplinar e interdisciplinar do processo saúde-doença, com maior possibilidade de articulação do médico com outras áreas do conhecimento, desde a graduação, contribuindo para uma formação mais humanística e afeita à valorização da dimensão ética.

\section{CONCLUSÕES}

O conteúdo de Ética e Bioética no currículo de Medicina da UFC tem espaço nas disciplinas específicas e, transversalmente, em boa parte das demais disciplinas do currículo, aspecto que merece ser incorporado ao currículo da UECE. A diversidade profissional do corpo docente da UECE, todavia, pareceu mais coerente com o desenvolvimento de uma formação generalista, com visão integral do ser humano e consciência de cidadania.

Sobre o desafio de desenvolver a ética da compreensão e da solidariedade mediante o aprender a ser e conviver, associado ao saber fazer e conhecer, em conexão com a totalidade, ambas as escolas apresentaram, por meio do método PBL, uma estratégia direcionada para o alcance dessa necessidade.

Avaliar em que medida essas propostas curriculares são suficientes para instaurar um novo paradigma ante as novas demandas sociais só poderá ter melhor curso em estudos posteriores, quando o tempo de maturação desta proposta for suficiente para uma análise capaz de apontar novas mudanças que priorizem o ensino da Ética e Bioética nas escolas de Medicina. Novos estudos deverão responder às questões relativas à evolução do pensamento e prática destes profissionais para uma visão mais humanística e cidadã, que apóie uma prática comprometida com a ética da solidariedade e da compreensão.

Enfim, o ato de estudar o lugar da Ética e Bioética na formação médica a partir da análise curricular identificou uma proposta mais tradicional para o curso de Medicina da UECE, que, entretanto, por ter apresentado um corpo docente multiprofissional, poderá redimensionar sua prática mais facilmente. Ao contrário, o curso da UFC, apesar de dispor de uma matriz curricular mais avançada, apresenta um corpo docente fechado na formação médica e mais dificilmente poderá desenvolver uma prática de ensino voltada para esse paradigma, pois é uma questão que passa pela contratação de professores e/ou transferência de professores de outras áreas afins, conquista para médio e longo prazos.

\section{REFERÊNCIAS}

1. Chauí M. Convite à filosofia. São Paulo: Ática; 1999.

2. Pegoraro OA. Ética e ciência: fundamentos filosóficos da Bioética. In: Palácios M, Martins A, Pegoraro AO org. Ética, ciência e saúde: desafios da Bioética. $1^{\text {a }}$. ed., Petrópolis (RJ): [s.n.]; 2002. p. 46-61.

3. Morin E. Os sete saberes necessários à educação do futuro. 8 ed. São Paulo: Cortez; 2003.

4. Dom Padim C. Ética e cidadania. In: Queiroz JJ org. Ética no mundo de hoje. São Paulo: Edições Paulinas; 1985. p.9-12.

5. Sá Júnior LSM. Ética do professor de Medicina. Bioética. 2002; 10 (1): 49-84.

6. D’ávila RL. É possível ensinar Ética Médica em um curso formal curricular? Bioética. 2002. 10(1): 115-26.

7. Schramm FR, Escosteguy CC. Bioética e avaliação tecnológica em saúde. Cadernos de Saúde Pública. 2000; 16(14): 951-61.

8. Trivinos ANS. Introdução à pesquisa em ciências sociais: pesquisa qualitativa em educação. São Paulo: Atlas; 1992.

9. Gil AC. Como elaborar projetos de pesquisa. 4. ed. São Paulo: Atlas; 2002.

10. Universidade Federal do Ceará (UFC). Projeto do curso de Medicina: um novo currículo. Fortaleza (CE): Pró-Reitoria de Graduação; 2001. (Série acadêmica).

11. Universidade Estadual do Ceará (UECE). Normas acadêmicas para o curso de Medicina. Fortaleza (CE): Pró-reitoria de raduação. Centro de Ciências da Saúde. Curso de Medicina; 2003.

12. Universidade Estadual do Ceará (UECE). Ementários das disciplinas obrigatórias Fortaleza (CE): Pró-reitoria de Graduação. Centro de Ciências da Saúde. Curso de Medicina; 2003.

13. Medicina de Sobral (MEDSOBRAL). Problem Based Learning (PBL). Disponível em: <http: / / www.medsobral.ufc.com.br. > Acesso em: 26 de abril de 2004. 
14. Siqueira JE, Sakai MH, Eisele RL. O ensino da ética no curso de Medicina: a experiência da Universidade Estadual de Londrina. Bioética. 2002; 10(1): 85-95.

15. Nicolescu B. Reforma da educação e do pensamento: complexidade e transdisciplinaridade. Disponível em: <http: / / www.cetrans.futuro.usp.br/>. Acesso em: 16 de maio de 2003.

16. Rego S. A formação ética dos médicos: saindo da adolescência com a vida (dos outros) nas mãos. Rio de Janeiro: Editora FIOCRUZ; 2003.

17. Silva JFR. A formação do médico. In: Marco MA org. A face humana da Medicina: do modelo biomédico ao modelo biopsicossocial. São Paulo: Casa do Psicólogo; 2003.

\section{Conflito de Interesses}

Declaramos que o artigo intitulado "O Lugar da Ética e Bioética nos Currículos de Formação Médica" resultou de incentivo e patrocínio dos próprios autores, que não receberam financiamento de qualquer agência de fomento, organizações ou instituições sem fins lucrativos. Ademais, destaque-se que os mesmos autores não possuem vínculo empregatício com agências ou instituições do gênero. $\mathrm{O}$ artigo também não apresentou Conflito de Interesses.

\section{Endereço para correspondência}

Annatália Meneses de Amorim Gomes

Rua Barbosa de Freitas, 1505 - apto.801 - Meireles 60170-020 - Fortaleza - CE

E-mail: annataliagomes@secrel.com.br 